\title{
Effect of Antioxidants on Pig Semen Cryopreservation to Preserve Sperm Fertility after Thawing
}

\author{
da Costa Silva RJ, da Silva MHM, Valadão L and \\ da Silva FM* \\ Department of Animal Reproduction, Faculty of Agrarian \\ Sciences and Environment Animal, University of the \\ Azores, IITAA, Portugal
}

*Corresponding author: Fernando Moreira da Silva, Department of Animal Reproduction, Faculty of Agrarian Sciences and Environment Animal, University of the Azores, IITAA, 9701-851 Angra do Heroísmo, Portugal

Received: July 02, 2021; Accepted: July 28, 2021; Published: August 04, 2021

\begin{abstract}
Boar semen cryopreservation has a high potential in the swine industry, allowing the large-scale use of genetically superior animals, improving efficiency, product quality, helping to reduce the risk of disease spread and gathering needs from the market. From a genetic point of view, semen freezing is desirable for genetic diversification, favouring a more efficient reproduction as well as the constitution of germplasm banks, including for repopulation in case of disease outbreak. However, freezing this semen for long periods for practical use is limited by the reduced viability and fertilization potential caused to sperm during the cryopreservation process and consequently low conception rates and smaller litters after artificial insemination. In part, the decrease in the fertilizing power of frozen spermatozoa may be associated with oxidative damage due to excessive formation of Reactive Oxygen Species (ROS), osmotic stress and cell damage due to ice formation during cryopreservation.
\end{abstract}

To suppress the damage caused by ROS, the present study was conducted to determine the impact of supplementation with three antioxidants, these being ascorbic acid, a-tocopherol and reduced glutathione, evaluating the parameters of semen quality, viability, total and progressive motility, vigour and agglutination rate after thawing. For this purpose, semen was collected from five boars, each being collected three times, at weekly intervals, always at the same time. Immediately after harvesting, the macroscopic (colour, appearance, and volume) and microscopic evaluation of the semen (mass motility, concentration, progressive individual motility, spermatic vigour and spermatic morphology) were evaluated. Subsequently, the semen was placed at $15^{\circ} \mathrm{C}$ for two hours and centrifuged at $800 \times \mathrm{g}$ for 10 minutes also at $15^{\circ} \mathrm{C}$, removing the supernatant. For the freezing medium, a base medium consisting of a commercial MR-A extender, supplemented with $3 \% \mathrm{v} / \mathrm{v}$ glycerol, $10 \% \mathrm{v} / \mathrm{v}$ egg yolk and $0.20 \%$ $\mathrm{w} / \mathrm{v}$ Sodium Dodecyl Sulfate (SDS) was used. The nine treatments used in the study were, respectively, ascorbic acid at concentrations of 100, 200 and $400 \mu \mathrm{L}, \alpha$-Tocopherol at concentrations of 200,400 and $800 \mu \mathrm{M}$ and reduced Glutathione at concentrations of 2.5, 5 and $10 \mathrm{mg} / \mathrm{l}$ and numbered as T1 to T9, respectively. In the control group, semen was frozen in a medium without adding any antioxidant. The semen belonging to the different treatments and to the control was placed in $0.25 \mathrm{ml}$ insemination French straws and incubated at $6^{\circ} \mathrm{C}$ for two hours. The subsequent freezing was carried out in nitrogen vapours $\left(-120^{\circ} \mathrm{C}\right)$ for ten minutes and immersed in liquid nitrogen after this period. After 7 days, the semen was thawed in a water bath at $37^{\circ} \mathrm{C}$ for 20 seconds, the straws dried on paper, placed on a microscope slide heated to $37^{\circ} \mathrm{C}$ and evaluated according to the parameters described above.

Regarding the comparison between the different treatments, it was observed that the sperm viability obtained in the treatments with ascorbic acid as well as glutathione reduced, was not statistically different from the control group. Higher values of ascorbic acid and reduced glutathione reduced sperm viability after thawing. As for the use of $\alpha$-tocopherol at a concentration of $400 \mu \mathrm{M}$, the best results of the entire study were obtained, with sperm viability of $31.52 \%( \pm 1.50)$. Regarding sperm motility and agglutination rate, a-tocopherol also showed the best results at the concentration of $200 \mu \mathrm{M}$, in which the mean sperm motility was $2.57 \pm 0.15$ and $2.07 \pm 0.15$, respectively.

The results of the present study allow us to infer that the addition of $200 \mu \mathrm{M}$ or $400 \mu \mathrm{M}$ of $\alpha$-tocopherol to the swine semen-freezing medium has a positive effect on sperm viability parameters after thawing.

Keywords: Reactive oxygen species; Antioxidants; Freezing; a-tocopherol; Glutathione; Ascorbic acid; Semen
Ann Agric Crop Sci - Volume 6 Issue 5 - 2021 ISSN: 2573-3583 | www.austinpublishinggroup.com da Silva et al. (C) All rights are reserved
Citation: da Costa Silva RJ, da Silva MHM, Valadão L and da Silva FM. Effect of Antioxidants on Pig Semen Cryopreservation to Preserve Sperm Fertility after Thawing. Ann Agric Crop Sci. 2021; 6(5): 1090. 


\section{Introduction}

The principle of cryopreservation is to conserve biological material by reversibly reducing cell metabolism, allowing the conservation of cells and tissues for indeterminate periods. In animal production, the cryopreservation of embryos and especially of gametes, has allowed, in addition to the constitution of germplasm banks, a great advance, since mainly for semen, after thawing and its use in artificial insemination has allowed a genetic evolution continuous improvement of phenotypic and genotypic characteristics of animals.

Regarding pigs, the conservation of semen through cryopreservation remains limited, given the reduction in the viability and fertility of the semen after its thawing, taking into account the percentage of returns and the number of piglets produced per litter, when compared with the results after using fresh or refrigerated semen. The low viability of spermatozoa observed after their thawing is associated with several factors, including oxidative damage, intracellular and extracellular ice formation during the semen cryopreservation/thawing processes, excess formation of Reactive Oxygen Species (ROS), osmotic stress, among others [1]. Free radicals produced by cells, and particularly sperm, are highly reactive groups of molecules, with one or more unpaired electrons. Its structure makes free radicals very susceptible to react with other molecules, oxidizing them, leading to a decrease in sperm motility, increased damage to sperm DNA, decreased efficiency in sperm fusion in oocytes, lipid peroxidation of the cell membrane, among others [2].

Given that the damage caused to swine sperm during their cryopreservation/thawing is more severe when compared to other species, there is also the need to understand the processes that can enable the maintenance of metabolism throughout the freezing and thawing procedure that allows keep its metabolic characteristics unchanged, making this semen capable of being used for artificial insemination. Antioxidants that, according to Halliwell and Gutteridge [3], can be defined as substances that, when present in low concentrations when compared to the oxidizable substrate, are capable of significantly inhibiting or delaying the oxidation of a substrate, have been widely studied with the aim to reduce damage caused by oxidative stress of sperm during cryopreservation [4]. Work carried out in this area has shown that the addition of antioxidants to semen has been beneficial in its protective action against oxidative damage. Estrada et al. demonstrated that the addition of ascorbic acid to semen significantly reduces $(p>0.05)$ sow returns to heat, increasing the total number of live born piglets per litter [5]. Giaretta and collaborators have also shown that reduced glutathione and ascorbic acid, when combined, have a beneficial effect on sperm freezing and thawing [6]. Particularly in swine, despite the known existence of enzymatic and non-enzymatic antioxidants, in seminal plasma, an imbalance between the total of antioxidants and ROS may occur, causing a state of oxidative stress. In a bibliographical research work, Moreira da Silva et al. [7] postulated that ROS might be of endogenous origin, through reductions of oxygen for energy production and as a byproduct, and of exogenous origin, for example, through chemical products and radiation forming free radicals from oxygen. Among these, the most common anion superoxide $\left(\mathrm{O}_{2}{ }^{-}\right)$, hydrogen peroxide $\left(\mathrm{H}_{2} \mathrm{O}_{2}\right)$, peroxyl radical $\left(\mathrm{ROO}^{-}\right)$and hydroxyl radical $\left(\mathrm{OH}^{-}\right)$. ROS, when in controlled amounts, are necessary for sperm capacitation, activation and fusion of sperm in oocytes, however, when they are present in high amounts, there is a disruption of the balance in cell metabolism, which can lead to cell death [8]. In order to counteract the imbalance caused by excess oxidants and associated cellular damage, antioxidants have the function of suppressing excess ROS and allowing stability in the levels of free radicals, which can act at three different levels: prevention, interception and repair.

Thus, the aim of this study was to evaluate the survival capacity of sperm during the freezing/thawing process of swine semen, changing the base medium with different concentrations of antioxidants, namely $\alpha$-Tocopherol, Ascorbic Acid and Reduced Glutathione. Several studies have demonstrated the success of antioxidant supplementation in freezing media, improving semen quality in response to increased fertility after sperm thawing [9]. The use of these antioxidant agents may represent a new approach to the preservation of frozen swine semen, allowing the development of Artificial Insemination (AI) strategies and protocols in the swine industry using frozen semen, avoiding the harmful imbalance of free radicals in the semen and obtaining results more consistent enabling its application on a large scale.

\section{Materials and Methods}

Semen collection was carried out in boars belonging to the artificial insemination center for pigs of the Agrarian Development Services of Ilha Terceira. In total, five males were used, each being collected 3 times, at weekly intervals, always at the same time.

The method used in all collections was the gloved hand technique with the use of a thermal cup with a filter on top, and the set was kept at a temperature of $37^{\circ} \mathrm{C}$ to avoid thermal shocks. The first fraction of the ejaculate was rejected because it contained little sperm concentration, and only the sperm-rich fraction of the ejaculate was used. After collection, the filter was removed and immediately macroscopic and microscopic evaluation of the semen was carried out using the protocol described by Westendorf et al. [10] with some modifications.

For the macroscopic evaluation, the semen was analysed taking into account the colour, appearance, and volume of the ejaculate, only samples whose appearance was opaque and creamy were used. Samples with different appearance were discarded. Regarding the microscopic evaluation, mass motility, concentration, progressive individual motility, spermatic vigor and spermatic morphology were evaluated using a Leica DFC 320 phase contrast microscope coupled to a digital image recording system.

Sperm motility was determined by evaluating at least 400 sperm in each semen sample. Each sperm was categorized as belonging to one of the four motility categories (fast progressive, slow progressive, non-progressive and immobile), using evaluation and quality control techniques. The values of motile sperm are, therefore, the sum of the two categories of motile sperm: fast progressive, slow progressive, based on Table 1 and 3 , and collections whose semen presented motility below $70 \%$ were rejected.

Sperm viability was evaluated using the eosin-nigrosin staining technique $[11,12]$. The staining solution for this evaluation was prepared by adding $67 \mathrm{~g}$ of eosin Y (CI 45380, VWR No 115935) and 
Table 1: Mass motility parameters evaluated during the study [15].

\begin{tabular}{|l|l|}
\hline \multicolumn{2}{|c|}{ Individual/Massal Motility Parameters } \\
\hline Rate 0 & Immobile sperm. \\
\hline Rate 1 & Slow and progressive motility sperm. \\
\hline Rate 2 & $\begin{array}{l}\text { Sperm with displacement in circles and some progressive (20 to } \\
40 \%) .\end{array}$ \\
\hline Rate 3 & Sperm with progressive motility and sinuous (40 to $60 \%)$. \\
\hline Rate 4 & Spermatozoa with progressive and very fast motility (60 to $80 \%)$. \\
\hline Rate 5 & Spermatozoa with progressive and very fast motility (>80\%). \\
\hline
\end{tabular}

Table 2: Pig semen agglutination rate assessment system [15].

\begin{tabular}{|c|c|}
\hline & Agglutination Rate \\
\hline Score & Percentage of agglutination \\
\hline Rate 0 & $0 \%$ \\
\hline Rate 1 & Low $(<10 \%)$ \\
\hline Rate 2 & Moderate $(10-25 \%)$ \\
\hline rate 3 & Severe $(>25 \%)$ \\
\hline
\end{tabular}

$10 \mathrm{~g}$ of nigrosin (CI 50420, VWR No 115924; $\mathrm{VWR}^{\mathrm{TM}}$ ) dissolved in $0.9 \%$ sodium chloride in one liter of distilled water. The solution was then brought to boiling and allowed to cool to room temperature $\left(20^{\circ} \mathrm{C}\right)$, after which it was filtered on filter paper $\left(90 \mathrm{~g} / \mathrm{m}^{2}\right)$ according to Bjoèrndahl et al. to retention of coarse and gelatinous precipitates at a low filtration speed $[13,14]$ and stored in a sealed dark glass bottle. Before use, the staining solution was brought to room temperature. In the staining process, the semen and eosin-nigrosin solution volume were approximately equal with the semen mixed on a microscope slide. Then a smear was made which was air dried and examined directly. At least 200 sperm were evaluated at $1000 \times$ magnification under oil immersion with a 100x high-resolution objective. White (unstained) sperm were classified as live and those with any pink or red color were classified as dead.

The agglutination degree was evaluated according to Gaczarzewicz et al., [15], in which the agglutination rate reflects the percentage of sperm in the field of view that are aggregated to others (Table 2). According to Gaczarzewicz et al., [15], the assessment of the agglutination rate indicates the percentage of sperm in the field of view that are in aggregate with others. This assessment was performed simultaneously with motility and vigor, using the data described in Table 2.

The $\mathrm{pH}$ was measured using a Sartorius Professional Meter PP-15 potentiometer calibrated daily.

Sperm concentration was determined with a Neubauer chamber, with a dilution of $10 \mu \mathrm{L}$ of semen to $990 \mu \mathrm{L}$ of water, according to Vianna et al., [16].

Subsequently, the semen was placed at $15^{\circ} \mathrm{C}$ for two hours and centrifuged at $800 \mathrm{x}$ g for 10 minutes also at $15^{\circ} \mathrm{C}$, removing the supernatant according to [17].

For the freezing base medium, MR-A was used, this being a commercial extender for semen refrigeration, which was supplemented with $3 \% \mathrm{v} / \mathrm{v}$ glycerol, $10 \% \mathrm{v} / \mathrm{v}$ egg yolk and $0.20 \%$ $\mathrm{w} / \mathrm{v}$ of SDS. In this medium, considered the base medium, $300 \mu \mathrm{L}$ of semen were added to each of the Falcon tubes to which $600 \mu \mathrm{L}$ of the dilution medium for each of the nine treatments were added (Table $4)$, and the viability was evaluated.

The semen was immediately packed in 0.25 Cassou straws (ref. IMV 005578-005701-005575-005585-005583) and incubated for two hours at $6^{\circ} \mathrm{C}$, being frozen in nitrogen vapors $\left(-120^{\circ} \mathrm{C}\right)$ according to Barros et al., [18]. In this step, the straws were cooled for 10 minutes in nitrogen vapor, 3 centimeters above the nitrogen level and submerged. After 7 days, the semen was thawed by shaking the straw with tweezers in a water bath at $37^{\circ} \mathrm{C}$ for 20 seconds [19]. Subsequently, the straws were dried on paper, the ends cut with scissors and their contents placed on a microscope slide heated to $37^{\circ} \mathrm{C}$ and evaluated for the parameters previously described for the semen immediately after collections.

Statistical analysis was performed using the SPSS statistical program. Descriptive statistics (mean, standard deviation) was used for all characteristics studied. Quantitative results were evaluated by analysis of variance (ANOVA), and when there was significance by the "F" test, the means were compared by Tukey's test with $5 \%$ probability of error.

\section{Results and Discussion}

So far, some research has been published on more consistent results in the conservation of swine semen, based on the use of antioxidants that reduce the oxidative stress of the semen, caused by Reactive Oxygen Species (ROS), which is pointed out as one of the main factors for the reduction of sperm viability during long-term conservation. An antioxidant is defined as any substance that, when present at low concentrations compared to an oxidizable substrate, significantly delays or prevents the oxidation of that substrate $[3,20]$. To protect itself from the lethal effect of excessive ROS formation, the cell has an antioxidant defense system, which can either remove the agent before the injury, or repair the damage that has occurred [3], whose mechanisms can be included. Basically on two antioxidant defense systems:

- Intracellular antioxidant defense system, which can be enzymatic, formed by the enzymes Superoxide Dismutase (SOD), catalase, Glutathione Peroxidase (GPx) and Reductase (GR).

- Another form of action of antioxidants is through a nonenzymatic process, formed by vitamins, ascorbic acid (vitamin C) and a-tocopherol (vitamin E).

In addition to oxidative stress, the cryopreservation process induces structural and biochemical damage to pig sperm, resulting in a drastic reduction in sperm viability after thawing. Thus, the aim

Table 3: Vigor Parameters (Intensity of movement and tail beat of spermatozoa) [36].

\begin{tabular}{|l|l|}
\hline \multicolumn{2}{|c|}{ Vigor Parameters } \\
\hline Rate 0 & Absence of sperm movement \\
\hline Rate 1 & Very slow and weak moving sperm \\
\hline Rate 2 & Slow-moving sperm (20 to $40 \%$ progressive) \\
\hline Rate 3 & Sperm with moderate movement (40 to 60\% progressive) \\
\hline Rate 4 & Fast-moving sperm (60 to $80 \%$ progressive) \\
\hline Rate 5 & Very fast moving sperm (>80\% progressive) \\
\hline
\end{tabular}


Table 4: Different antioxidants used in boar semen freezing media and their concentrations.

\begin{tabular}{|c|c|}
\hline Treatments & Concentration \\
\hline Control & 0 \\
\hline T1 - Ascorbic acid & $100 \mu \mathrm{M}$ \\
\hline T2 - Ascorbic acid & $200 \mu \mathrm{M}$ \\
\hline T3 - Ascorbic acid & $400 \mu \mathrm{M}$ \\
\hline T4 - - - Tocopherol & $200 \mu \mathrm{M}$ \\
\hline T5 - $\alpha$-Tocopherol & $400 \mu \mathrm{M}$ \\
\hline T6 - $\alpha$-Tocopherol & $800 \mu \mathrm{M}$ \\
\hline T7 - Reduced Glutathione & $2.5 \mathrm{mg} / \mathrm{l}$ \\
\hline T8 - Reduced Glutathione & $5.0 \mathrm{mg} / \mathrm{l}$ \\
\hline T9 - Reduced Glutathione & $10.0 \mathrm{mg} / \mathrm{l}$ \\
\hline
\end{tabular}

of the present work was to evaluate the effect of different antioxidants at different concentrations in swine semen during its preparation for freezing, evaluating its characteristics after thawing. Two nonenzymatic antioxidants (vitamin $\mathrm{C}$ (ascorbic acid) and vitamin $\mathrm{E}$ ( $\alpha$ tocopherol)) were used to protect sperm from oxidative damage in cells and cell organelles, as well as an enzymatic antioxidant (reduced glutathione). Treatments ( $\mathrm{T}$ ) were numbered from 1 to 9, as indicated in Table 4. Semen from five pigs was collected three times for each boar, frozen with the antioxidants described above and the results obtained after thawing, namely sperm viability, degree of agglutination and quality of spermatic movement were evaluated approximately one week after freezing (Table 4). For a value of $\mathrm{P}$ $\leq 0.05$, the results were considered statistically different.

\section{Effect of cryopreservation on sperm viability}

The evaluation of live sperm was determined by the EosinNigrosin method, the results being expressed as a percentage. This test is based on the evaluation of cell membrane integrity, in which nonviable sperm allow the entry of dye (eosin) and the sperm heads show a reddish color [21]. Therefore, eosin is a supravital dye that does not penetrate cells with an intact plasma membrane, but when damaged, they are stained pink. Nigrosin is responsible for the darker contrast that is seen at the bottom of the slide, which allows the visualization of unstained sperm. This coloration was first described in 1951 by Swanson and Bearden [22] and has since been widely used (Table 5).

Of the various techniques currently described to analyze sperm viability, namely the use of fluorescent probes [23], and the hyposmotic test, originally developed to verify the functionality of the plasma membrane of human sperm [24], double staining with eosin/ nigrosin is the best indicator of living/dead cells.

In the present work, as only colorless sperm were considered alive, that is, they did not allow the penetration of any amount of dye; this could be the reason for the low viability values observed throughout the study.

Regarding the comparison between the different treatments, we can observe that the sperm viability obtained in the treatments with ascorbic acid (T1, T2 and T3) was identical to that observed for the control group. Although there was a slight increase in viability observed at T1, no statistically significant differences were observed
Table 5: Result of the different parameters of boar semen evaluation for the different treatments. Each value represents the mean \pm standard error of the results obtained for the $5 * 3$ evaluations performed.

\begin{tabular}{|c|c|c|c|}
\hline Treatments & Motility (0-5) & Agglutination level (0-5) & Viability (\%) \\
\hline Fresh semen & $4.7 \pm 0.10$ & $1.33 \pm 0.08$ & $48.36 \pm 2.40$ \\
\hline Control & $2.03 \pm 0.18$ & $2.27 \pm 0.20$ & $27.93 \pm 1.21$ \\
\hline T1 & $2.37 \pm 0.16$ & $2.27 \pm 0.15$ & $28.18 \pm 1.83$ \\
\hline T2 & $2.33 \pm 0.17$ & $2.27 \pm 0.18$ & $26.70 \pm 1.90$ \\
\hline T3 & $2.27 \pm 0.12$ & $2.13 \pm 0.16$ & $26.40 \pm 1.84$ \\
\hline T4 & $2.57 \pm 0.15$ & $2.07 \pm 0.15$ & $29.30 \pm 1.68$ \\
\hline T5 & $2.47 \pm 0.17$ & $2.13 \pm 0.16$ & $31.52 \pm 1.50$ \\
\hline T6 & $2.50 \pm 0.17$ & $2.27 \pm 0.15$ & $27.88 \pm 2.64$ \\
\hline T7 & $2.40 \pm 0.13$ & $2.40 \pm 0.13$ & $29.32 \pm 2.73$ \\
\hline T8 & $2.23 \pm 0.14$ & $2.33 \pm 0.15$ & $28.04 \pm 1.52$ \\
\hline T9 & $2.30 \pm 0.16$ & $2.27 \pm 0.15$ & $22.87 \pm 2.43$ \\
\hline
\end{tabular}

between these two treatments. By analyzing Figure 1, we see that apparently higher values of ascorbic acid reduced sperm viability after semen thawing. Previous work carried out with this antioxidant, namely for the freezing of Human semen, has been shown to have a positive effect on DNA protection, with no effect on sperm morphology after thawing [25]. In other species (e.g. equine; carp,...), the addition of ascorbic acid, as in the present study, did not increase sperm viability after thawing $[26,27]$. Although the results with this antioxidant added to the freezing medium did not significantly increase the semen characteristics after thawing, work developed by Dawson et al., [28] demonstrated that the addition of this vitamin for a period of 4 weeks in concentration of $1 \mathrm{~g} /$ day, considerably improved the quality of the semen, with respect to motility, concentration and sperm morphology.

Regarding the use of a tocopherol, it was observed that in treatments $\mathrm{T} 4, \mathrm{~T} 5$ and $\mathrm{T} 6$, which represent, respectively, the addition of a -tocopherol, at concentrations 200, 400 and $800 \mu \mathrm{M}$, it was observed that $\mathrm{T} 5$ obtained the best result of the entire study, with sperm viability of $31.52( \pm 1.50)$.

Previous studies by several authors demonstrate that vitamin E intake improves seminal quality in humans $[29,30]$, bulls and horses [31]. Its in vitro addition to semen after collection and freezing was also postulated to improve sperm quality after thawing, in different species, namely in cattle and horses, where a higher quality of intact sperm was observed as well as a decrease in lipoperoxidation after its thawing [32].

\section{Effect of cryopreservation on sperm motility}

The mean values obtained for sperm motility after thawing are shown in Figure 2. As can be seen, there was, for all treatments, a trend towards increased sperm motility compared to the control group $(2.03 \pm 0.18)$, with the best results being obtained for the treatment with $\alpha$-tocopherol, at a concentration of $200 \mu \mathrm{M}$ (T4), in which the mean sperm motility was $2.57 \pm 0.15$, this value being statistically different $(\mathrm{P}<0.05)$ when compared with the result obtained for the control group.

Several studies demonstrate a positive relationship between sperm 


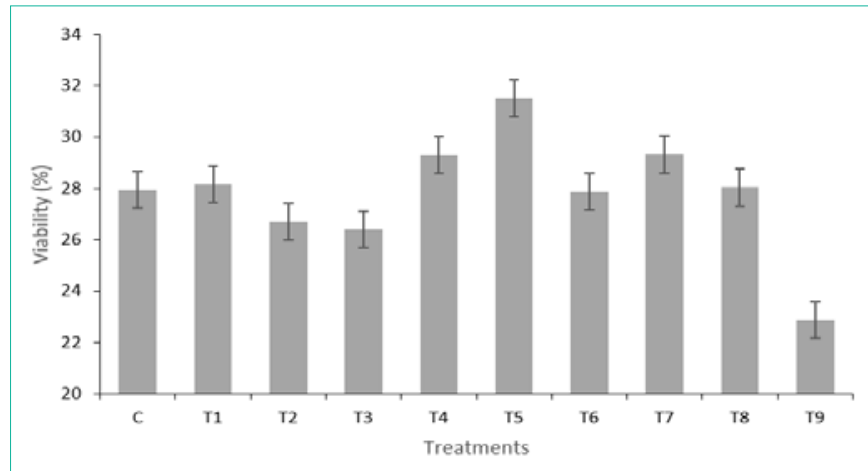

Figure 1: Result of sperm viability obtained for different treatments. Each value represents the mean \pm standard error of the results obtained for the $5 * 3$ evaluations performed.

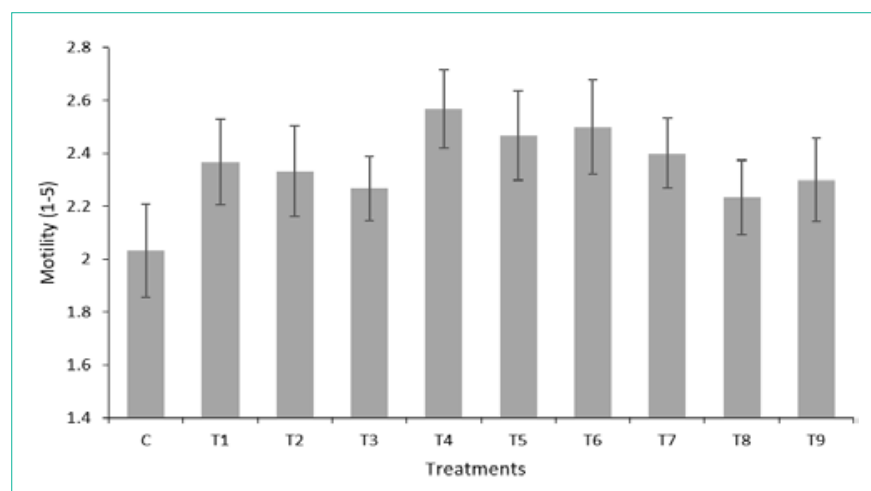

Figure 2: Motility result for different antioxidant treatments. Each value represents the mean \pm standard error of the results obtained for the $5 * 3$ evaluations performed.

motility and successful fertilization [33-36] semen evaluation factor one of the most important criteria in the evaluation of the fertilizing capacity of males. In the present study, sperm motility was evaluated considering the semen's ability to move in one direction, using the technique previously described by Deschamps and Pimentel [37]. This test complements the viability test, as it has been shown that in both fresh [38] and frozen [36] ejaculates, there is a proportion of sperm that are viable even when immobile, it can acquire motility after stimulation with different reagents, namely caffeine [39], or once in the female's reproductive system. Although motility is generally correlated with plasma membrane integrity [40], this direct correlation does not yet meet with consensus. However, in the present work, the addition of alpha-tocopherol to the freezing extender exerted a protective effect on the sperm plasma membrane, improving seminal motility after thawing. Since $\alpha$-tocopherol is a structural antioxidant of the plasma membrane that acts at the extracellular level, and most agents act in the intracellular environment, it could be an indicator of the importance of protecting the plasma membrane against the excessive generation of ROS.

The occurrence of membrane damage potentiates lipid peroxidation and consequent DNA fragmentation [41]. The observed loss of sperm vigor is a common feature of frozen sperm, due to several factors including heat shock and osmotic stress caused by the cryopreservation process [42]. The low loss of spermatic vigor observed in treatments $\mathrm{T} 4$ and $\mathrm{T} 5$ can be explained by the fact

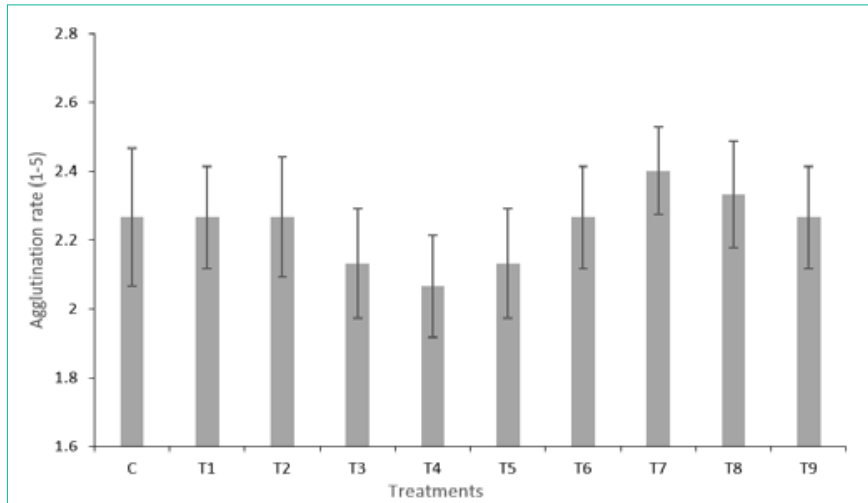

Figure 3: Agglutination result for different antioxidant treatments. Each value represents the mean \pm standard deviation of the results obtained for the $5 * 3$ evaluations performed.

that the antioxidant $\alpha$-tocopherol provides protection during the cryopreservation of these spermatozoa. The concentration of 200 and $400 \mu \mathrm{M}$ of $\alpha$-tocopherol had a positive effect during cryopreservation, and its use was beneficial in the evaluated parameters of swine spermatozoa. On the other hand, considering the location of a-tocopherol in subcellular membranes, Kefer et al. [8] postulated that this vitamin mainly removes ROS that participate in biological oxidation. Donnelly et al. [43] suggested that although the addition of $\alpha$-tocopherol in freezing media can reduce sperm motility, the use of this antioxidant can positively influence the results of semen preservation in different species. Results similar to those obtained in the present study were obtained by Donnelly et al., [43], who, when adding vitamin $\mathrm{E}$ to human semen samples, obtained a reduction in the production of oxidants, with an improvement in sperm motility/ viability after thawing. It should also be noted that the effects of vitamin E could vary depending on the concentration used. It is known that according to the amount of free radicals to be inactivated, it may have an antioxidant action or to stimulate oxidation [44].

\section{Effect of cryopreservation on sperm agglutination}

The results of the evaluations carried out on the degree of agglutination are shown in Figure 3. Note that, as observed in the results of viability and motility, the most optimistic results were observed in treatment 4 .

Sperm agglutination specifically refers to motile sperm glued together, head-to-head, tail-to-tail, or in a mixed fashion. Under normal conditions, sperm agglutination should be almost nonexistent, and it is suggested that this factor is one of the causes of low fertility when present, since sperm agglutination makes it difficult for them to move along the female genital tract, directly affecting the fertility of these sperm. Although some studies show that frozen and stored semen induces sperm agglutination [45], there are other factors evidenced in studies that showed that if bacterial contaminations occur during storage, they potentiate the appearance of agglutinations [46].

Furthermore, temperature fluctuations during freezing were also indicated as a possible source of sperm agglutination [47]. Particularly in pigs, it has been described that in addition to these conditions, acidification of the medium ( $\mathrm{pH}$ between 5.7 and 6.4) may also cause 
agglutination [48].

However, despite the $\mathrm{pH}$ changes being presented with a sperm agglutination factor, for each treatment the $\mathrm{pH}$ was measured immediately after collection and the end of refrigeration, however, there were no conditions for this evaluation after thawing.

In several studies, $\alpha$-tocopherol has been widely used in extenders during the freezing of semen from other species, which provides effective protection during the cryopreservation of these sperm. The application of $200 \mu \mathrm{M}$ of a-tocopherol had a positive effect during cryopreservation, and its use was beneficial in the evaluated parameters of pig spermatozoa. However, further studies on conception rate and litter size employing frozen and thawed sperm supplemented with $\alpha$-tocopherol in artificial insemination would provide more interesting and reliable information that would increase the use of frozen semen by the swine industry. After examining the data, we can also conclude that high concentrations had no beneficial effect on the conservation of swine semen. Some authors, including Zimmermann and Kirsten [49], warned that high concentrations of this vitamin could potentiate other problems in cell metabolism, and our results are similar.

\section{Conclusions and Future Perspectives}

Although the mechanisms of action of antioxidants in the protection of swine sperm cells are not completely clear, our results indicate that concentrations between $200-400 \mathrm{mM}$ of $\alpha$-tocopherol, in the semen-freezing medium of this species, have a positive effect on sperm preservation in relation to the data obtained in the control group. The motility, viability and sperm agglutination rates of these treatments allow the use of semen eventually for artificial insemination.

Further studies on conception rate and litter size using artificial insemination with thawed semen supplemented with $\alpha$-tocopherol would provide more concrete information that would increase the use of frozen semen by the swine industry. It is important to highlight the lack of detailed studies on the effect of sperm agglutination on fertility.

\section{Declaration}

Acknowledgement: This project was financed in $85 \%$ by FEDER and in $15 \%$ with regional funds through the "Programa Operacional Açores 2020 (Operational Program Azores 2020), in scope of the project Cryotec-ACORES-01-0145-FEDER-000092".

Thanks are due to Mr. Jorge Armas and Mr. Mario Coelho for the precious help with boar's semen collecting. work.

Authors' Contributions: All authors equally contributed in this

\section{References}

1. Agarwal A, Saleh RA \& Bedaiwy MA. Role of reactive oxygen species in the pathophysiology of human reproduction. Fertility and Sterility. 2003; 79: 829-843.

2. Agarwal A, Prabhakaran S \& Sikka S. Clinical relevance of oxidative stress in patients with male factor infertility: Evidence-based analysis. AUA Update Series. 2007; 26: 1-12

3. Halliwell B \& Gutteridge JMC. Free Radicals in Biology and medicine. ( $2^{\text {th }}$ ed.), Oxford University Press. Oxford. 1999.

4. Guerra MMP, Evans G \& Maxwell WMC. Role of oxidants and antioxidants in andrology. Revista Brasileira de Reprodução Animal. 2004; 28: 187-195

5. Estrada E, Rodríguez-Gil JE, Rocha LG, Balasch S, Bonet S \& Yeste M. Supplementing cryopreservation media with reduced glutathione increases fertility and prolificacy of sows inseminated with frozen-thawed boar semen. Andrology. 2014; 2: 88-99.

6. Giaretta E, Estrada E, Bucci D, Spinaci M, Rodríguez-Gil JE \& Yeste M Combining reduced glutathione and ascorbic acid has supplementary beneficial effects on boar sperm cryotolerance. Theriogenology. 2015; 83: 399-407.

7. Moreira da Silva F, Marques A \& Chaveiro A. Reactive Oxygen Species: A Double-Edged Sword in Reproduction. The Open Veterinary Science Journal. 2010; 4: 127-133.

8. Kefer J, Agarwal A \& Sabanegh E. Role of antioxidants in the treatment of male infertility. International Journal of Urology. 2009; 16: 449-457.

9. Bucak MN, Ateşşahin A, Varışlı Ö, Yüce A, Tekin N \& Akçay A. The influence of trehalose, taurine, cysteamine and hyaluronan on ram semen. Microscopic and oxidative stress parameters after freeze-thawing process. Theriogenology. 2007; 67: 1060-1067.

10. Westendorf $P$, Richter $L$ \& Treu $H$. Deep freezing of boar sperma. Laboratory and insemination results using the Hülsenberger paillete method. Deutsche tierarztliche Wochenschrift. 1975; 82: 261.

11. Mortimer D. The male factor in infertility. Part I: Semen analysis. Current problems in Obstetrics, Gynecology and Fertility. 1985; 7: 75-76.

12. Mortimer D. Sperm recovery techniques to maximize fertilizing capacity. Reproduction, Fertility and Development. 1994; 6: 25-31.

13. Kvist $U$ \& BjoÈrndahl L. Basic semen analysis. ESHRE Monographs. Universidade de Oxford Press, Oxford, Reino Unido. 2000a.

14. Kvist U \& BjoÈrndahl L. Editorial to the manual on Basic Semen Analysis. Basic Semen Analysis. ESHRE Monographs, Universidade de Oxford Press, Oxford, United kingdom. 2000b.

15. Gaczarzewicz D, Udala J, Piasecka M, Blaszczyk B \& Stankiewicz T. Bacterial contamination of boar semen and its relationship to sperm quality preserved in commercial extender containing gentamicin sulfate. Polish Journal of Veterinary Sciences. 2016; 19.

16. Vianna WL, Bruno DG, Namindome A, Rosseto AC, Rodrigues PHM, Pinese $M E$, et al. Estudo comparativo da eficiência de diferentes técnicas de mensuração da concentração espermática em suínos. Revista Brasileira de Zootecnia. 2004; 33: 2054-2059.

17. Martinez-Alborcia MJ, Morell JM, Gil MA, Barranco I, Maside C, Alkmin DV, et al. Suitability and effectiveness of single layer centrifugation using Androcoll-P in the cryopreservation protocol for boar spermatozoa. Animal Reproduction Science. 2013; 140: 173-179.

18. Barros MHC, Shiomi HH, Amorim LS, Guimarães SEF, Lopes PS, Siqueira $\mathrm{JB}$, et al. Criopreservação de sêmen de suínos da raça Piau submetido a três protocolos de congelamento. Revista Brasileira de Zootecnia. 2012; 41: 914-922.

19. Maxwell WMC \& Johnson LA. Membrane status of boar spermatozoa after cooling or cryopreservation. Theriogenology. 1997; 48: 209-219.

20. Toniolli R, Toniollo GH, Francheschini PH \& Morato FMAC. Uso do diluente BTS no processo de congelação do sêmen suíno: Il. Modificações na técnica. Ciência Animal. 2015; 25: 44-59.

21. Barth AD \& Oko RJ. Abnormal Morphology of Bovine Spermatozoa. lowa State University Press. 1989; 285.

22. Swanson EW \& Bearden HJ. An Eosin-Nigrosin Stain for Differentiating Live and Dead Bovine Spermatozoa. Journal of Animal Science. 1951; 10: 981987.

23. Harrison RA \& Vickers SE. Use of fluorescent probes to assess membrane integrity in mammalian spermatozoa. Journal of reproduction and fertility. 
1990; 88: 343-352.

24. Jeyendran RS, Van der Vem HH, Perez-Pelaez M, Crabo BG \& Zaneveld LJ. Development of an assay to assess the functional integrity of the human sperm membrane and its relationship to other semen characteristics. Journal of reproduction and fertility. 1984; 70: 219-228.

25. Garvez MES. Efeito do resveratrol e do ácido ascórbico na criopreservação de sêmen humano. Tese de Doutoramento em Biotecnologia. Universidade de Caxias do Sul. Caxias do Sul. 2011; 5: 73-81.

26. Sampaio BFB. Addition of vitamin C, AA2G, a-tocopherol and docosahexaenoic acid to the cooling extender of equine semen. Tese de Doutoramento em Ciência Animal, Universidade Federal de Mato Grosso do Sul. 2015; 52-55.

27. Linhares FRA. Effect of vitamins added to the ACP-104 extender on the quality of cryopreserved semen of common carp (Cyprinus carpio). Arquivo Brasileiro de Medicina Veterinária e Zootecnia. 2017; 69: 980-988.

28. Dawson EB, Harris WA, Teter MC \& Pwell LC. Effect of ascorbic acid supplementation on the sperm quality smokers. Fertility and sterility. 1992 58: 1034-1039

29. Kobori Y, Ota S, Sato R, Yagi H, Soh S, Arai G, et al. Antioxidant cosupplementation therapy with vitamin $C$, vitamin $E$, and coenzyme Q10 in patients with oligoasthenozoospermia. Arquivo Italiano de Urologia e Andrologia. 2014; 86: 1.

30. Nadjarzadeh A, Mehrsai A, Mostafavi E, Gohari MR \& Shidfar F. The association between dietary antioxidant intake and semen quality in infertile men. Medical Journal of the Islamic Republic of Iran. 2013; 27: 204-209.

31. Contri A, Amicis I, Molinari A, Fastini M, Gramenzi A, Robbe D, et al. Effect of dietary antioxidante supplementation of fresh semen quality in stallion. Theriogenology. 2011; 75: 1319-1326.

32. Franco JV, Chaveiro A, Góis A \& Silva FM. Effects of a-tocopherol and ascorbic acid on equine semen quality after cryopreservation. Journal of Equine Veterinary Science. 2013; 33: 787-793.

33. Kjaestad H, Ropstad E \& Andersen BK. Evaluation of spermatological parameters used to predict the fertility of frozen bull semen. Acta Veterinaria Scandinavica. 1993; 54: 299-303.

34. Bailey JL, Robertson L \& Buhr MM. Calcium regulation, computerized motility parameters and the fertility of bovine spermatozoa. Canadian Journal of Animal Science. 1994; 74: 53-58.

35. Stålhammar EM, Janson L \& Philipsson J. The impact of sperm motility on non-return rate in preselected dairy bulls. Reproduction Nutrition Development. 1994; 34: 37-45
36. Januskauskas A, Johannisson A \& Rodriguez-Martinez H. Subtle membrane changes in cryopreserved bull semen in relation with sperm viability, chromatin structure, and field fertility. Theriogenology. 2003; 60: 743-758.

37. Deschamps JC \& Pimentel CA. Exame de sémen em touros. Boletim técnico, n¹2. UFPel, Publicação avulse. 1979; 29

38. Casey PJ, Hillman RB, Robertson KR, Yudin Al, Liu IK \& Drobnis EZ. Validation of an acrosomal stain for equine sperm that differentiates between living and dead sperm. Journal of Andrology. 1993; 14: 289- 297.

39. Larsson K, Einarsson S \& Nicander L. Influence of Thawing Diluents on Vitality, Acrosome Morphology, Ultrastructure and Enzyme Release of DeepFrozen Roar Spermatozoa. Acta Veterinaria Scandinavica. 1976; 17: 83-100.

40. Kumi-Diaka J. Subjecting canine semen to the hypo-osmotic test. Theriogenology. 1993; 39: 1279-1289.

41. Jeong YJ, Kim MK, Song HJ, Kang EJ, Ock SA, Kumar BM, et al. Effect of alpha-tocopherol supplementation during boar semen cryopreservation on sperm characteristics and expression of apoptosis related genes. Cryobiology. 2009; 58: 181-189.

42. Watson PF. The causes of reduced fertility with cryopreserved semen. Anima Reproduction Science. 2000; 61: 481- 492.

43. Donnelly E, McClure N \& Lewis S. Antioxidant supplementation in vitro does not improve human sperm motility. Fertility and Sterility. 1999; 72: 484-495.

44. Cao G \& Cutler RG. High concentration of antioxidants may not improve defense against oxidative stress. Archives of Gerontology and Geriatrics. 1997; 17: 189-201

45. Yeste M, Briz M, Pinart E, Sancho S, García-Gil N, Badia E, et al. Hyaluronic acid delays boar sperm capacitation after 3 days of storage at 15 degrees $\mathrm{C}$. Animal Reproduction Science. 2008; 109: 236-250.

46. Dong Q, Huang C \& Tiersch TR. Control of sperm concentration is necessary for standardization of sperm cryopreservation in aquatic species: evidence from sperm agglutination in oysters. Cryobiology. 2007; 54: 87-98.

47. Althouse GC, Kuster CE, Clark SG \& Weisiger RM. Field investigations of bacterial contaminants and their effects on extended porcine semen. Theriogenology. 2000; 53: 1167-1176.

48. Lorenzioni SRG. Criopreservação de sémen equino envasado em criotubo. Dissertação de mestrado. Faculdade Veterinária, Universidade Federal do Rio Grande do Sul, Porto Alegre. 2010.

49. Zimmermann AM \& Kirsten VR. Alimentos com função antioxidante em doenças crônicas: uma abordagem clínica. Disciplinarum Scientia. 2008; 9: 51-68. 